\title{
CRISE DA DEMOCRACIA CONTEMPORÂNEA, POBREZA E DESIGUALDADE: RUMO AO DESENVOLVIMENTO (IN)SUSTENTÁVEL?
}

\author{
Isadora K. Lazaretti* \\ Giovanni Olsson ***
}

\section{Resumo:}

A superação da pobreza faz-se necessária para o enfrentamento da crise da democracia contemporânea. O objetivo geral consiste em compreender essa crise a partir da efetivação do desenvolvimento sustentável. A metodologia baseou-se na técnica predominantemente bibliográfica. Os últimos anos revelaram uma involução democrática marcada por crises reprodutoras ativas de desigualdades. O Estado tornou-se incapaz de garantir de forma plena os direitos sociais. A pobreza e as desigualdades se estendem às populações a passos largos, atingindo elementos que não estão unicamente relacionados à distribuição de renda. $\mathrm{O}$ direito ao desenvolvimento sustentável permanece distante de ser efetivado do ponto de vista multidimensional.

Palavras-chave: Democracia. Pobreza. Desigualdade. Desenvolvimento sustentável.

\section{CONTEMPORARY DEMOCRACY CRISIS, POVERTY, AND INEQUALITY: TOWARDS (UN)SUSTAINABLE DEVELOPMENT?}

\begin{abstract}
:
Overcoming poverty is necessary to face the crisis of contemporary democracy. The general objective is to understand this crisis based on the realization of sustainable development. The methodology was based on the predominantly bibliographic technique. The last few years have revealed a democratic involution marked by active reproductive crises of inequalities. The state has become unable to fully guarantee social rights. Poverty and inequality are spreading to populations at a rapid pace, reaching elements that are not solely related to income distribution. The right to sustainable development remains far from being realized from a multidimensional point of view.
\end{abstract}

Keywords: Democracy. Poverty. Inequality. Sustainable development.

\section{INTRODUÇÃO}

O tema do desenvolvimento sustentável vem atraindo, nas últimas décadas, a atenção para discussões em diversos campos do conhecimento. Esse termo tem aparecido com

\footnotetext{
" Doutoranda em Direito pela Universidade do Oeste de Santa Catarina, com bolsa de doutorado integral pela Coordenação de Aperfeiçoamento de Pessoal de Nível Superior - CAPES. Mestra em Direito pela Universidade Comunitária da Região de Chapecó - UNOCHAPECÓ. E-mail: iklazaretti@gmail.com.

** Professor do Programa de Pós-Graduação em Direito da Universidade Comunitária da Região de Chapecó UNOCHAPECÓ. Doutor em Direito pela Universidade Federal de Santa Catarina - UFSC. E-mail: golsson71@gmail.com.
} 
tamanha recorrência nos debates internacionais diante da infinidade de desafios sociais, econômicos, ambientais e políticos desencadeados por modelos de crescimento econômico, que foi a tônica desde o fim da Segunda Guerra Mundial.

Não é de hoje que as disfuncionalidades da democracia vêm sendo altamente contestadas. Da mesma forma, ao lado de autores como Castells (2018) e Runciman (2018), é possível afirmar que a democracia se encontra, nos dias atuais, em uma verdadeira crise. Corrupção, descrença em regimes democráticos, desigualdade e crises econômicas são alguns exemplos de fatores que contribuíram para essa realidade.

Dessa forma, o presente trabalho tem como objetivo contribuir para o debate que envolve a análise da crise da democracia contemporânea, a pobreza e a desigualdade, que constituem temas relevantes no momento atual, especialmente quando estudados e relacionados sob a ótica do desenvolvimento sustentável em sua multidimensionalidade. Especificamente, tem-se como objetivos: (i) estudar a pobreza e suas complexidades conceituais para além do senso comum; (ii) vislumbrar a(s) crise(s) da democracia contemporânea e a promessa descumprida da igualdade, a partir do projeto filosófico da modernidade compreendido por Boaventura de Sousa Santos; e (iii) verificar as implicações do déficit democrático para o desenvolvimento sustentável multidimensional na questão da pobreza.

Justifica-se a pesquisa pela importância de estudar o fenômeno da pobreza multidimensional, que deixou de ser considerada apenas do ponto de vista de uma insuficiência monetária, passando a abranger vários fatores que podem consistir em necessidades humanas e, consequentemente, prejudicar o desenvolvimento e a subsistência. Além disso, o debate sobre a pobreza, por si só, intenta tornar mais clara e analítica essa terminologia, assim como possibilitar a busca de formas eficazes para a solução desse grave problema social. A pobreza, infelizmente ainda atinge a população mundial em larga escala, desafiando as premissas do desenvolvimento sustentável e a própria configuração da democracia.

Em termos metodológicos, a abordagem do problema foi feita por meio de pesquisa bibliográfica, envolvendo a coleta livros e publicações nacionais e internacionais, voltadas à realização de uma revisão de literatura prévia. Os materiais escolhidos pelos autores sobre a temática da "democracia" foram selecionados a partir das obras nacionais e estrangeiras. A pesquisa bibliográfica foi realizada também com base na análise de documentos eletrônicos 
na língua portuguesa, espanhola e inglesa. Na sua maioria, foram obtidos por meio de pesquisa junto à plataforma OPHI*, cuja busca foi realizada através de termos chave, utilizando-se a expressão "pobreza multidimensional" além de outras plataformas eletrônicas usadas com esses mesmos critérios de busca. Quanto à abordagem do desenvolvimento sustentável, o levantamento bibliográfico se deu a partir dos documentos temáticos constantes na base de dados do sítio eletrônico das Nações Unidas e também da seleção de obras publicadas em língua inglesa, exceto livros de coletâneas.

\section{A POBREZA E SUAS COMPLEXIDADES CONCEITUAIS: OLHANDO PARA ALÉM DO SENSO COMUM}

Conceituar a pobreza constitui uma tarefa complexa, tendo em vista que seu significado abrange inúmeras faces totalmente interconectadas, que vão além do mero aspecto da quantidade e disponibilidade de renda individual, que há muito ocupam o centro do debate. Para tanto, e nas últimas décadas, a academia vem promovendo inúmeras reflexões para alargar o seu conceito e melhor compreender suas implicações sobre a dignidade humana.

O que é pobreza e como ela se mede são questionamentos feitos, por exemplo, por Amartya Sen. Para ele, um aspecto da pobreza expressa-se pela "incapacidade de buscar bemestar precisamente pela falta de meios econômicos" (SEN, 2001, p. 173). Essa interpretação faz com que a pobreza seja compreendida a partir do seu aspecto mais tradicional, isto é, ligado à privação ou insuficiência de renda.

Contudo, essa visão da pobreza é aquela que se corrobora com a percepção do senso comum. Este, por sua vez, é definido por Santos como "o conhecimento vulgar e prático com que, no quotidiano, orientamos as nossas ações e damos sentido à nossa vida" (2008, p. 88). Trata-se, assim, do conhecimento não-científico, que aceita uma verdade sem discussão, porque, ainda segundo Santos, o conhecimento do senso comum se reproduz de forma espontânea no mundo da vida, aceitando o que existe de tal forma como existe.

Não é nenhuma novidade, portanto, que as visões mais aceitas do conceito atual de pobreza partem de um âmbito multidimensional, que considera o impacto de diversos indicadores de vulnerabilidade nas condições de vida das populações. Nessa linha, definir a

\footnotetext{
"Oxford Poverty \& Human Development Iniciative. Disponível em: https://ophi.org.uk/. Acesso em: 20 abr. 2020.
} 
pobreza para além da insuficiência de recursos monetários não diz respeito apenas ao "não reconhecimento da validade do uso da renda dos indivíduos/famílias como proxy para a identificação de públicos-alvo de políticas públicas ou [...] para a celebração de diagnósticos voltados à diminuição da pobreza" (MELLO, 2018, p. 36), porque, para além desta visão, devem ser considerados como relevantes outros fatores de carência que afetam os indivíduos mais pobres.

Para além do senso comum, o conceito de pobreza deve ser separado da noção de dependência de padrões de subsistência mínima das classes mais baixas, deixando de se considerar tão somente o aspecto econômico, isto é, a renda. Essa ideia de pobreza deve ser substituída, como propõe Mencher (1972, p. 83), “por uma medida do nível mínimo que a sociedade pode tolerar em vista de seus objetivos nacionais", de modo que "mesmo onde uma renda mínima possa ser considerada suficiente pelos seus detentores imediatos, ela pode ser altamente inadequada na forma em que afeta o bem-estar econômico e social da nação como um todo".

Por isso, a visão sobre a pobreza abrange hoje o que Amartya Sen (2000) chama de "privação de capacidades", abarcando uma visão desenvolvimentista, da qual fazem parte outros elementos essenciais ao bem-estar individual que vão além da renda, como a educação, a saúde, o saneamento básico, a cultura e a inclusão, por exemplo. A partir da teoria da abordagem das capacidades, desenvolvida por Sen (2000), o conceito de pobreza passou a ter um enfoque mais humano, considerando o bem-estar do indivíduo em prol do desenvolvimento econômico, na medida em que passa a se relacionar diretamente com a liberdade de oportunidades e a liberdade de escolha que cada indivíduo tem em relação a seus objetivos de vida.

Ele afirma que as capacidades são "liberdades substantivas" que permitem ao indivíduo escolher uma vida, a partir de objetivos, que se tenha razão para promover e valorizar. Essa capacidade consiste, na "combinação alternativa de funcionamentos cuja realização é factível para ela" (SEN, 2000, p. 104). O autor apresenta nessa teoria o conceito de "funcionamentos", que são reflexos de coisas que um indivíduo pode ter ou possuir, desde um funcionamento elementar, ate atividades, estados pessoais ou complexos. Coisas que podem ser "valorizadas", como, por exemplo, ser adequadamente nutrido, estar saudável e livre de doenças e poder participar da vida da comunidade (SEN, 2000, p. 104-105). 
Assim, a pobreza deve ser vista como a privação das capacidades básicas em vez de meramente como baixo nível de renda, segundo a concepção de Amartya Sen.

Alkire et al compreendem a multidimensionalidade da pobreza como uma condição pela qual as pessoas estão expostas a múltiplas desvantagens - reais e potenciais - que englobam, além da baixa renda, a falta de moradia, desemprego, privação da educação, saúde, transporte, água e saneamento, além da presença de dimensões psicológicas, como violência, humilhação, dependência e vergonha (2015, p. 3).

O estudo da pobreza avançou ao longo dos últimos anos, com a criação e o emprego de metodologias destinadas a medir ela. Feres e Mancero (2001), por exemplo, realizaram essa tarefa a partir de uma abordagem das necessidades básicas insatisfeitas. Mais recentemente, Alkire e Foster (2011) criaram uma metodologia específica de contagem voltada para a medição da pobreza, baseada em estimativas de um Índice Multidimensional de Pobreza (IPM), que anualmente são publicadas e analisadas para mais de 100 países em desenvolvimento nos Relatórios de Desenvolvimento Humano do Programa das Nações Unidas para o Desenvolvimento (PNUD). Entretanto, longe de aprofundar tais métodos de medição da pobreza, estes indicadores permitem tão somente demonstrar alguns pressupostos e referências existentes para a compreensão desse fenômeno.

Por fim, o conceito de pobreza diz respeito às privações e às insuficiências nas diversas esferas da vida. Como ressaltado por Narayan, a pobreza engloba tanto o bem-estar econômico como o bem-estar social, abrangendo, especialmente, questões que envolvem dignidade humana, democracia, liberdade, igualdade dentre outras expressões. Para ele, "entender a pobreza de tal maneira difere das definições dos estudos ortodoxos, que geralmente se concentram nas pessoas que vivem abaixo da linha de pobreza de renda" (2012, p.35).

Mello, a seu turno, considera que a caracterização de uma situação de pobreza abrange dimensões como a insegurança alimentar, o acesso precário à água e ao saneamento básico, as altas taxas de mortalidade, os baixos níveis de escolarização, a restrição de oportunidades de geração de renda e a precarização do trabalho diante de longas jornadas e de baixos salários, por exemplo. A pobreza reside em cada uma dessas dimensões, na medida em que, segundo a autora, "ser afetado por uma ou mais dessas carências produz consequências significativas sobre a qualidade de vida de milhões de pessoas [...]" e, ainda, "sobre suas 
possibilidades de acessar bens e serviços necessários para garantir condições adequadas de sobrevivência" (2018, p. 36).

Assim, possuir bens acima da média do seu contexto social, isoladamente, não exclui o indivíduo do âmbito da pobreza, se ele estiver privado de liberdade ou de canais de participação democrática ou de acesso concreto a oportunidades de educação e socialização. Esse recorte multidimensional da pobreza, como se observa, e sob diversas perspectivas, é fundamental para avançar no debate sobre suas relações e inferências com a democracia e sua crise.

Por isso, e debatida a pobreza para além do senso comum, numa perspectiva multidimensional, passa-se a analisar o contexto da crise da democracia contemporânea e a promessa descumprida da igualdade a partir do projeto filosófico da modernidade.

\section{A(s) crise(s) da democracia contemporânea e a promessa descumprida da igualdade}

Um Estado eficaz no cumprimento de seu papel político pressupõe um sistema jurídico e ao mesmo tempo democrático, que tem o condão de garantir um patamar mínimo de direitos civis, sociais e políticos ao indivíduo. A ideia de democracia expressa, consequentemente, a garantia e a efetivação desses direitos.

Nessa linha, o Estado é visto por O`Donnel (2004, p. 13) a partir de três dimensões: como um conjunto de entes burocráticos, como um sistema legal e como um foco de identidade coletiva, que expressam três aspectos: eficácia, efetividade e credibilidade. Entretanto, essas três dimensões nem sempre operam de forma plena, na medida em que muitas vezes o sistema legal é falho, e o Estado não se mostra efetivo como um garantidor dos direitos mínimos.

A democracia contemporânea passa pelo crescente questionamento sobre seu fracasso. Como destaca Runciman a respeito da falsa representação, “o espetáculo passou a significar pouco para nós: reduziu-se a um desempenho estéril e artificial” (2018, p. 108), em que a hipocrisia discursiva e a retórica descomprometida passam a ocupar a agenda e o espaço públicos.

Nas últimas décadas, vários foram os acontecimentos que contribuíram para a crise da democracia: crises econômicas, denúncias de corrupção, catástrofes ambientais e a redução 
de direitos básicos da pessoa humana, por exemplo. Todos esses acontecimentos vieram acompanhados de promessas de esperança absorvida pela população em grande parte do mundo com descrença. O sentimento de desconfiança do povo ocasionou uma reprovação moral do Estado.

Castells (2018, p. 5), nessa toada, afirma a existência de uma crise de legitimidade, porque, do ponto de vista político, existe, de fato, uma falsa representação, porque os atores políticos fundamentais teriam se transformado em um grupo social que defende seus interesses comuns acima dos interesses daqueles que, em tese, dizem representar. Representantes passam a imprimir agendas próprias, descoladas dos interesses e das agendas dos representados, num bizarro jogo de falsa representação.

Em uma crise de legitimidade, como denominada por Castells (2018, p. 10), “aquilo que era um modelo de representação desmorona na subjetividade das pessoas", na medida em que os cidadãos têm frustradas as esperanças depositadas no exercício da democracia.

A compreensão da democracia tornou-se algo além da representação política e da periódica (re)escolha de representantes. Atualmente, há muitas outras maneiras de se aferir a democracia em um ente político. Novas formas de legitimidade surgem para complementar a democracia, o que indica que ela esteja embarcando em uma nova era.

Não se pode olvidar que a democracia abrange um conjunto de direitos e configura, inclusive, um limite ao poder estatal. A democracia implica que cada indivíduo seja titular de direitos fundamentais, que, em suas diversas dimensões, compõem o acervo de direitos que permitem a ampla e plena dignidade da pessoa humana e são considerados como direitos sem os quais é impossível pensar no desenvolvimento democrático de uma sociedade fraterna e pluralista.

Contudo, na contemporaneidade, apenas nos foi garantida uma implementação limitada desses direitos, especialmente porque se verifica um verdadeiro regresso de uma série de direitos sociais (O`DONNEL, 2004).

O estado atual da democracia foi influenciado de forma direta pelo advento da globalização econômica. Os avanços no campo das tecnologias resultaram paradoxalmente tanto na libertação do indivíduo como no seu aprisionamento. Isso porque "a tecnologia que tem o poder de nos libertar contém, também, os piores cenários possíveis, envolvendo abusos imensos de poder, crescimento da desigualdade e paralisia política" (RUNCIMAN, p. 185). 
Pode-se considerar, assim, que a crise da democracia liberal é o resultado de acontecimentos que se sucederam nas últimas décadas e que ainda se manifestam no atual cenário. A emergência da globalização fez com que as economias nacionais se desestruturassem com as insuficiências regulatória sobre atores e ações globalmente articuladas acima e para além das fronteiras estatais. O Estado, até então considerado o centro de decisão, visto como um ente capaz de resolver as problemáticas no âmbito de seu território, restou enfraquecido simultaneamente dentro e fora de seu recorte territorial, incapacitado de cuidar de problemas globais como terrorismo, mudanças climáticas, crises financeiras e violação de direitos humanos (CASTELLS, 2018).

Também se ressaltam as crises financeiras, que podem ser consideradas reprodutoras ativas das desigualdades. A democracia se mostrou enfraquecida quando o Estado sofreu déficit na eficácia de suas instituições. Os direitos sociais, por exemplo, estão longe de ser efetivados. Pelo contrário, verifica-se uma verdadeira negação a tais direitos, se considerarmos que a pobreza e as desigualdades sociais ampliam-se nos povos a passos largos.

Outros fatores também merecem menção: guerras, catástrofes ambientais e desastres são exemplos que tornaram perceptíveis os riscos à democracia. $\mathrm{Na}$ medida em que os riscos para a existência humana passaram a ofuscar outros tipos de ameaças, a democracia passou a se desvigorar (RUNCIMAN, 2018). Ressalta-se que a maioria desses eventos advém da ação do homem. Nesse viés, cabe destacar o texto de Rachel Carson (1969), denominado Primavera Silenciosa, em que adverte: "não tinha sido um feitiço, nem uma ação inimiga, que extinguira a vida naquele mundo agonizante. Era obra das próprias pessoas".

Não se trata de uma calamidade ambiental, mas o trecho acima perpassa a ideia do destino da democracia, se observado o caminho que está seguindo. Runciman (2018, p. 185) denomina o fenômeno de crise de meia-idade da democracia, e considera que, "para chegarmos ao melhor futuro possível, precisamos nos dispor a enfrentar o pior", na medida em que "a democracia que a tantos inspira antipatia e desconfiança continua a ser um lugar familiar e confortável, se comparada à perspectiva do desconhecido".

Esse complexo panorama revela que o projeto filosófico da modernidade, visto como "rico, capaz de infinitas possibilidades, e, como tal, muito complexo e sujeito a desenvolvimento contraditórios" (SANTOS, 1997, p. 71), trouxe promessas que não foram 
totalmente cumpridas. Seu descumprimento parte, primeiramente, da promessa do Estado como garantidor de um mínimo de direitos.

Apesar de sua formação ter se iniciado a partir do século XVI, muito antes do capitalismo ter se tornado o modo de produção dominante, o projeto filosófico da modernidade veio a tomar corpo apenas no final do século XVIII, período em que se iniciaram os testes de cumprimento das promessas realizadas (SANTOS, 1997). Esse projeto resultou numa série de transformações sociais, e marcado pelo fenômeno da globalização nas suas feições mais recentes, notadamente como modernidade tardia.

A modernidade foi pensada por Habermas (2000) como um ideal de desenvolvimento de um mundo novo que se direciona para o futuro. Essa ideia de mundo novo trouxe uma série de modificações no campo social que se manifestaram de forma intensa em várias esferas do mundo da vida.

Sustentado pelos pilares da emancipação e da regulação, o projeto filosófico da modernidade, segundo Santos (1997), manifestou-se a partir de dois processos: o processo de superação, que expressa a premissa de que o projeto da modernidade cumpriu algumas de suas promessas enquanto outras foram cumpridas em excesso, e, ainda, pelo processo de obsolescência, que, segundo Santos, caracterizou-se pelo fato de que a modernidade se tornou irremediavelmente incapaz de cumprir com o que prometeu.

Isso demonstra que a modernidade se apresenta como uma situação de crise, ou, ainda, uma situação vazia, porque os pilares da modernidade - regulação e emancipação - já não mais se sustentam. Ainda que fosse visto como um projeto ambicioso e revolucionário sob a perspectiva das Revoluções Francesa e Americana, incorporando o homem como centro da vida moderna emergente, não se pode negar que o ideário da modernidade contemplou um excesso de promessas e um défice no seu cumprimento (SANTOS, 1997). Assegurar o desenvolvimento de valores como solidariedade, igualdade e liberdade deixou de ser uma realidade plausível diante das mudanças paradigmáticas às quais a sociedade foi submetida.

Se, de fato, a modernidade é incapaz de cumprir com outras de suas promessas, pode-se considerar que algumas delas, como, por exemplo, a promessa da igualdade, estejam bem longe de serem efetivadas. O tópico anterior, inclusive, demonstra tal realidade, na medida em que a pobreza assola diversas partes do mundo e prevalecem as desigualdades sociais, e não se pode dizer que, como seres humanos, somos efetivamente iguais, a par da retórica jurídica. 
A igualdade pode até ter sido garantida no discurso dos direitos humanos, positivada formalmente nas cartas políticas dos Estados como um direito fundamental. Porém, essa garantia é puramente formal, haja vista que se tornou habitual, por exemplo, uma democracia sem participação do povo, a existência de desigualdades sociais, a pobreza, a substituição da força de trabalho humana pela automação e a utilização da natureza como mero objeto de exploração de recursos, dentre outros aspectos interconectados que se retroalimentam na espiral de distanciamento dos seres humanos nas suas necessidades mais elementares.

Desenhado esse cenário, passa-se, assim, especificamente para a análise das implicações do défice democrático para o desenvolvimento sustentável pluridimensional na questão da pobreza.

\section{IMPLICAÇÕES DO DÉFICIT DEMOCRÁTICO PARA O DESENVOLVIMENTO SUSTENTÁVEL PLURIDIMENSIONAL NA QUESTÃO DA POBREZA}

A compreensão inicial do desenvolvimento sustentável pode ser realizada a partir do histórico Relatório de Brundtland, da Comissão Mundial sobre Meio Ambiente e Desenvolvimento, conhecido como "Nosso Futuro Comum". Naquele documento, ele é definido como "aquele que atende as necessidades do presente sem comprometer a possibilidade de as gerações futuras atenderem a suas próprias necessidades” (1987, n.p).

Não por acaso, o discurso do desenvolvimento sustentável há muitos anos vem sendo palco de intensos debates. Entretanto, teve maior destaque recente com o advento da Agenda 2030 da Organização das Nações Unidas (ONU), com a instituição dos Objetivos de Desenvolvimento Sustentável (ODS) em 2015, e constitui um novo projeto civilizatório que elenca ações e medidas para os próximos anos em áreas de importância crucial para a humanidade e para a vida no planeta.

Ela é resultado da Cúpula das Nações Unidas sobre o Desenvolvimento Sustentável, onde mais de 150 líderes mundiais se reuniram para discutir uma plataforma de ação da comunidade internacional e dos governos nacionais na busca da prosperidade e do bem-estar comum. Por isso, a Agenda 2030 da ONU constitui um plano universal ambicioso, integrado e transformador que tem como escopo primordial o de não deixar ninguém para trás (ONU, 2015). 
Além de buscar prosperidade, a Agenda 2030 visa fortalecer a paz universal entre as nações. Sua instituição, assim como o seu cumprimento, conta com a participação de todos os países e partes interessadas, a partir de uma atuação em parceria colaborativa desses agentes, e busca-se o alcance dos objetivos propostos para a promoção do desenvolvimento sustentável.

Nesse sentido, merece destaque o que dispõe o Preâmbulo da Agenda 2030, quando menciona que "a erradicação da pobreza em todas as suas formas e dimensões, incluindo a pobreza extrema, é o maior desafio global e um requisito indispensável para o desenvolvimento sustentável” (ONU, 2015, n.p). O Preâmbulo revela ainda que a Agenda 2030 tem como intuito a libertação da humanidade da pobreza e da penúria com a adoção de medidas urgentes, ousadas e transformadoras ao alcance de um mundo sustentável e resiliente (ONU, 2015).

Como restou escrito no Relatório de Brundtland, da Comissão Mundial sobre Meio Ambiente e Desenvolvimento, "satisfazer as necessidades e aspirações humanas é o principal objetivo do desenvolvimento" (1987, n.p). O desenvolvimento sustentável tem como escopo atender as necessidades humanas tanto pelo aumento do potencial produtivo como pela garantia de oportunidades iguais para todos. Também considerado como "um processo de mudança no qual a exploração dos recursos, o direcionamento dos investimentos, a orientação do desenvolvimento tecnológico e a mudança institucional estão em harmonia" e "reforçam o atual e futuro potencial para satisfazer as aspirações e necessidades humanas" (1987, n.p), o desenvolvimento sustentável constitui o tema central da Agenda 2030.

É importante atentar que tem se tornado cada vez mais difícil o alcance dos objetivos e metas da Agenda 2030, especialmente quando pensados nas diversas esferas do desenvolvimento pluridimensional. A falta de prioridades pelos próprios entes estatais, na adoção de políticas públicas destinadas à promoção do desenvolvimento sustentável, constitui exemplo dessas dificuldades. A precariedade do financiamento às ações destinadas ao alcance das metas e objetivos também colabora para essa realidade.

A seu turno, a Agenda 2030 das Nações Unidas preocupa-se com um dos maiores desafios globais do milênio: a erradicação da pobreza em todas as suas formas e dimensões. Entretanto, nesse contexto de desigualdade formal e material, caracterizado por pobreza em todos os sentidos, torna-se ainda mais difícil a garantia do desenvolvimento sustentável e seu avanço às dimensões ambiental, econômica e social. 
Não por acaso, os pobres enfrentam grandes desafios estruturais que os impedem de se inserir, e, consequentemente, de alcançar o desenvolvimento nas demais dimensões. As ferramentas para a erradicação da pobreza propostas por Sachs (2005) caracterizam-se pela instituição de planos e sistemas, pela responsabilidade mútua e pela criação de mecanismos de financiamento, porque, na sua concepção, esse aparato em funcionamento seria, no mínimo, uma possibilidade de alcançar o almejado fim da pobreza.

A erradicação da pobreza constitui o Objetivo n. 1 da Agenda 2030 (acabar com a pobreza em todas as suas formas, em todos os lugares) e tem-se como metas: $(i)$ "erradicar a pobreza extrema para todas as pessoas em todos os lugares, atualmente medida como pessoas vivendo com menos de US\$ 1,90 por dia"; (ii) "reduzir pelo menos à metade a proporção de homens, mulheres e crianças, de todas as idades, que vivem na pobreza, em todas as suas dimensões, de acordo com as definições nacionais"; (iii) “implementar, em nível nacional, medidas e sistemas de proteção social adequados, para todos, incluindo pisos, e até 2030 atingir a cobertura substancial dos pobres e vulneráveis"; (iv) "garantir que todos os homens e mulheres, particularmente os pobres e vulneráveis, tenham direitos iguais aos recursos econômicos, bem como o acesso a serviços básicos [...]"; (v) "construir a resiliência dos pobres e daqueles em situação de vulnerabilidade, e reduzir a exposição e vulnerabilidade destes a eventos extremos relacionados com o clima e outros choques e desastres econômicos, sociais e ambientais"; (vi) "garantir uma mobilização significativa de recursos a partir de uma variedade de fontes, inclusive por meio do reforço da cooperação para o desenvolvimento, para proporcionar meios adequados e previsíveis para que os países em desenvolvimento [...]" e (vii) “criar marcos políticos sólidos em níveis nacional, regional e internacional, com base em estratégias de desenvolvimento a favor dos pobres e sensíveis a gênero, para apoiar investimentos acelerados nas ações de erradicação da pobreza" (2015, n.p).

O problema da pobreza e das desigualdades assume contornos dramáticos em várias regiões do mundo há muitas décadas. Segundo Sachs (2015), estima-se que, aproximadamente, 1,2 bilhão de pessoas ainda vivem abaixo da linha de pobreza do Banco Mundial, de \$1,25 dólares por pessoa por dia. Pensando em nível mundial, as regiões mais afetadas pela pobreza são a África, com aproximadamente 413 milhões de pessoas em situação de extrema pobreza, e o sul da Ásia, cujo número é de 507 milhões. Outros 100 milhões de pessoas espalham-se nas outras regiões do mundo, como na América Latina e Caribe, Europa e Ásia central. Apesar desse elevado número, o problema da pobreza parece, 
nos dias atuais, ser menosprezado pelas potências mundiais e pelos próprios Estados, que, incapazes de garantir na íntegra os direitos fundamentais do indivíduo, deixam de priorizar ações, de realizar estudos e de destinar recursos para programas para sua erradicação eficaz.

Pesquisas recentes realizadas pelo Programa das Nações Unidas para o Desenvolvimento (PNUD) apontam que a desigualdade ainda é cruel na América Latina, considerada a região mais desigual do mundo. Embora todos os países da região, exceto a Argentina, Venezuela e Nicarágua, tenham melhorado o Índice de Desenvolvimento Humano, ainda assim os níveis de desigualdade permanecem altíssimos. Países como Brasil, México, Colômbia, Chile, Paraguai e Panamá são exemplos dos casos mais paradigmáticos que demonstram como as desigualdades relacionadas à renda são responsáveis pela redução do progresso social. Além disso, o Brasil é considerado como o responsável pela maior parte da pobreza nos últimos cinco anos, e perdeu 23 posições no ranking de classificação da ONU considerando o fator da inequidade (EL PAIS, 2019). Nesses indicadores, o alongamento da pirâmide econômica e social é uma realidade corrente: um número cada vez menor de pessoas no topo possui riqueza dezenas de vezes maior que o restante, cada vez mais achatado na base.

Também é possível mencionar o Chile, que, inserido numa crise política e social, retrocedeu 14 posições no ranking da ONU, quando permaneceu como exemplo de política de liberalização econômica da América Latina durante décadas, levando-se em consideração apenas um dos muitos indicadores mais difundidos: a medida de distribuição de renda do Coeficiente de Gini. Segundo a ONU, o caso chileno é o que se vislumbra de forma mais clara quando os dados são analisados a partir dos protestos, de modo que as desigualdades de renda e a discriminação refletem diretamente no bem-estar social (EL PAIS, 2019).

Na medida em que este cenário assim se desdobra, as desigualdades sociais tomam cada vez mais espaço, dando lugar, inclusive, à regressão da democracia. O desamparo econômico, social, político, cultural e ambiental, ou qualquer que for sua dimensão, reflete de forma direta na democracia. Mais do que uma forma de governo pautada na igualdade, na participação e na decisão coletiva sobre os rumos da sociedade, a democracia configura um instrumento para a proteção, garantia e realização dos direitos fundamentais.

A esse respeito, Sobrinho (2018, p.1295) considera que, "quanto mais diversidade, melhor o funcionamento da democracia”, ao mesmo tempo que quanto maior a inclusão social e a participação, maior será o grau de democratização de direitos e, consequentemente, 
prevalência da dignidade humana. No mesmo sentido, O`Donnel considera que o indivíduo nunca deveria ser tratado como um súdito suplicante da boa vontade do governo, na medida em que é titular de um conjunto de direitos civis, sociais e políticos e deve ser tratado com plena consideração e respeito a esses direitos (2004).

Tem-se, assim, que a superação da pobreza configura um pressuposto inicial para permitir alavancar a questão democrática e o próprio desenvolvimento pluridimensional. É desnecessário insistir que aqueles que fazem parte da parcela da população que está com fome ou morando debaixo da ponte não ocupam efetivamente o espaço democrático, não são representados e não se fazem representar exatamente por não serem considerados cidadãos no sentido mais amplo. Para esses, e na escala de necessidades e prioridades, obter alimento e proteção para as intempéries, por exemplo, vem muito antes e acima das inquietações do debate de representação político-partidária. Não por acaso, a pobreza e as desigualdades revelam um verdadeiro regresso aos direitos sociais e, consequentemente, à própria democracia.

Verifica-se, assim, um cenário marcado por desigualdade, tanto de caráter formal, como de caráter material, caracterizado pela pobreza em vários sentidos, em especial na relativização dos direitos civis, políticos e sociais que terminam por refletir na dignidade da pessoa humana.

Por fim, não se pode deixar de considerar que o direito ao desenvolvimento, na qualidade de direito fundamental (e humano) de terceira geração, dotado de relevância, de caráter multifacetário, reconhecido como um direito de solidariedade, permanece distante de ser plenamente efetivado. O mesmo ocorre quanto ao desenvolvimento sustentável e ao plano de ação da Agenda 2030, como um projeto civilizatório a ser alcançado, em particular, no alcance do ODS destinado a erradicar a pobreza em todos os lugares.

\section{CONCLUSÃO}

Este trabalho propôs uma análise introdutória da democracia contemporânea, da pobreza multidimensional e das desigualdades, sob a ótica da realização do desenvolvimento sustentável. Teve como problemática investigar se o desenvolvimento sustentável pode ser alcançado, considerando, para tanto, a crise da democracia do atual cenário e a falsa promessa 
de uma sociedade igualitária e o alcance dos objetivos da erradicação da pobreza e da redução das desigualdades elencados na Agenda 2030 das Nações Unidas.

A era contemporânea revela uma involução democrática marcada por crises de naturezas diversas, reprodutoras ativas de desigualdades. Verifica-se um verdadeiro enfraquecimento da democracia, em que o Estado sofreu um déficit na eficácia de suas instituições, tornando-se incapaz de garantir de forma plena os direitos sociais. Pelo contrário, verifica-se uma negação a tais direitos, se considerarmos que a pobreza e as desigualdades se estendem às populações a passos largos, atingindo vários elementos que não estão unicamente relacionados à distribuição de renda.

Embora o projeto filosófico da modernidade tenha prometido liberdade, igualdade e fraternidade, verificou-se um descumprimento dessas promessas, sobretudo no que diz respeito à igualdade. Em um cenário marcado por desigualdades, tanto de caráter formal, como de caráter material, caracterizado pela pobreza em vários sentidos, a relativização dos direitos civis, políticos e sociais termina por refletir na democracia e no desenvolvimento sustentável.

A pobreza está longe de ser interpretada como a ideia ultrapassada do senso comum, ligada exclusivamente ao critério econômico, isto é, à insuficiência de renda. Hoje, esse conceito se tornou multidimensional e se expressa em diversos aspectos do mundo da vida. A pobreza engloba não apenas o bem-estar econômico, mas questões ligadas à dignidade humana, liberdade, igualdade, acesso, oportunidades, pleno emprego, saúde, educação, saneamento básico, segurança e democracia, dentre outras.

A erradicação da pobreza e a superação das desigualdades, assim, constituem pressupostos essenciais para permitir o alcance dos objetivos do desenvolvimento pluridimensional e, consequentemente, para alavancar a própria democracia como participação política. Não custa lembrar que o indivíduo privado de alimento ou de moradia, por exemplo, não pode ser considerado como cidadão no sentido mais amplo, não é representado e nem se faz representar, além de que lhe são negados uma série de direitos fundamentais que o Estado prometeu garantir.

Enquanto este panorama se desdobra de tal forma, o direito ao desenvolvimento permanece distante de ser efetivado de forma sustentável, e a democracia, como valor coletivo, fica mais próxima de uma retórica vazia do que uma realidade palpável na vida contemporânea. 


\section{REFERÊNCIAS BIBLIOGRÁFICAS}

ALKIRE, Sabina; FOSTER, James. Counting and multidimensional poverty measurement. Journal of Public Economics, Oxford, v. 95, n. 7-8, p. 476-487, 2011.

ALKIRE, Sabina; SANTOS, Maria Emma. Poverty and inequality measurement. In: DENEULIN, S.; SHAHANI, L. An introduction to the human development and capability approach: freedom and agency. Londres: Earthscan, 2009, p. 121-161.

CASTELLS, Manuel. Ruptura: a crise da democracia liberal. Tradução Joana Angélica d'Avila Melo. Rio de Janeiro: Zahar, 2018.

EL PAIS. A desigualdade ofusca o tímido avanço da América Latina no desenvolvimento humano. 2019. Disponível em:

https://brasil.elpais.com/brasil/2019/12/09/economia/1575893151_006065.html. Acesso em: 10 jan. 2020.

CARSON, Rachel. Primavera silenciosa. Tradução Raul de Polillo. 2 ed. Edições Melhoramentos: São Paulo, 1969.

FERES, Carlos; MANCERO, Xavier. Enfoques para la medición de la pobreza: breve revisión de la literatura. Santiago do Chile: Cepal, 2001.

HABERMAS, Jürgen. O discurso filosófico da modernidade: doze lições. Tradução de Luiz Sério Repa e Rodnei Nascimento. São Paulo: Martins Fontes, 2000.

MELLO, Janine. Estratégias de superação da pobreza no Brasil e impactos no meio rural. Rio de Janeiro: IPEA, 2018.

NARAYAN, Deepa. The dynamics of poverty. In: ORTIZ, Isabel; DANIELS, Louise Moreira; ENGILBERTSDÓTTIR, Sólrún (Eds.). Child poverty and inequality: new perspectives. United Nations Children's Fund (UNICEF), Division of Policy and Practice, New York: 2012, p. 35-42.

O’DONNELL, Guillermo et al. Notas sobre la democracia em América Latina. La democracia en América Latina. Hacia una democracia de ciudadanas y ciudadanos, p. 11-82, 2004.

ORGANIZAÇÃO DAS NAÇÕES UNIDAS. Relatório de desenvolvimento Humano 2014 (sustentar o progresso humano: reduzir as vulnerabilidades e reforçar a resiliência). [online]. 2014. Disponível em: http://www.pnud.org.br/arquivos/RDH2014pt.pdf. [online] 2014.

Acesso em: 06 jan. 2020. 
Our future common. Disponível em: http://www.un-documents.net/ocf-02.htm\#I. Acesso em: 16 jan. 2020.

Transforming our world: the 2030 Agenda for Sustainable Development. 2015. Disponível em: https://sustainabledevelopment.un.org/post2015/transformingourworld. Acesso em: 03 jan. 2020.

SACHS, Jeffrey D. The end of poverty: economic possibilities for our time. The Penguin Press: New York, 2005.

SANTOS, Boaventura de Sousa. Pela mão de Alice: o social e o político na pósmodernidade. Porto: Edições Afrontamento, 1997.

SEN, Amartya. Desenvolvimento como liberdade. Tradução de Laura Teixeira Motta. São Paulo: Companhia das Letras, 2000.

Record, 2001.

Desigualdade reexaminada. Tradução Ricardo Doninelli Mendes. Rio de Janeiro: 1983.

Poor, relatively speaking. Oxford Economic Papers, v. 35 n. 1, p.153-169, Mar.

SOBRINHO, Afonso Soares Oliveira. Pobreza, democracia e desenvolvimento humano no século XXI: a ética dialógica do direito no acesso à justiça. Revista de Direito da Cidade, vol. $10, \mathrm{n}^{\circ} 2$. ISSN $2317-7721$ pp. 1275-1300.

RUNCIMAN, David. Como a democracia chega ao fim. Trad. Sergio Flaksman. São Paulo: Editora Todavia, 2018.

VIEIRA, Carine de Almeida; KUHN, Daniela Dias; MARIN, Solange Regina. Método Alkire-Foster: uma aplicação para a medição de pobreza multidimensional no Rio Grande do Sul (2000-2010). Revista Planejamento e políticas públicas, n. 48, jan./jun. 2017, p. 267298. 